Christian, J. I. (1972). Soil structure interaction for tall buildings. Conf. on planning and design of tall buildings. Lehigh Univ., Bethlehem, Pennsylvania.

Gibson, R. E. (1967). Some results concerning displacements and stresses in a non-homogeneous elastic half-space. Géotechnique 17, No. 1, 58-67.

Gibson, R. E. \& Sills, G. C. (1971). Some results concerning the plane deformation of a non-homogeneous elastic half-space. Proc. Roscoe Memorial, Cambridge.

Klein, G. K. (1956). Heterogeneous half-space and interaction between soil and structure. Sbornik Trudov Moskovskij Inz. Strait. Inst. No. 14.

Klein, G. K. \& Durajev, A. E. (1971). The effect of the increase of modulus of deformation of soil with increasing depth for calculation of beams on a continuous foundation. Gidiotechnicheskope Stroiticlstro No. 7.

\title{
Correlation between Atterberg plasticity limits and residual shear strength of natural soils
}

VOIGHT, B. (1973). Géotechnique 23, No. 2, 265-267.

\section{P. K. De and B. Furdas, Sir William Halcrow and Partners, Aberaman, Aberdare, Glamorgan}

We welcome Voight's Note as a contribution to a better understanding of the physical properties of natural soils in relation to the residual shear strength.

During the investigation of active spoil tips in South Wales, attempts were made to relate shear strengths of soil samples to their Atterberg limits. Most of the available drained shear box test results were on colliery spoil and boulder clay, a few on silty-sandy clay, one on Keuper marl and one on peaty clay.

The following graphs were plotted:

(a) ratio of residual shear strength to normal pressure $\left(\tau_{r}^{\prime} / \sigma\right)$ against plasticity index for the colliery spoil and natural soils separately;

(b) $\left(\tau_{\mathrm{r}}^{\prime} / \sigma\right)$ against the ratio of plastic limit to liquid limit for the colliery spoil and natural soils separately;

(c) brittleness index $\left(\tau_{\mathrm{f}}^{\prime}-\tau_{\mathrm{r}}^{\prime}\right) / \tau_{\mathrm{f}}^{\prime}$ against plasticity index and against PL/LL for colliery spoil and the natural soils separately and combined.

Little or no correlation was obtained with the plots involving colliery spoil, which is not surprising as Voight pointed out in his Note that in non-natural soils the trend of increasing $I p$ for decreasing $\mu_{r}^{\prime}$ is not observed in all cases. Also, no correlation was obtained with the plots involving brittleness index as expected, as the brittleness index is a function of peak and residual shear strengths. The former is dependent on many factors, such as stress history and initial moisture contents.

The plots of $\left(\tau_{r}^{\prime} / \sigma\right)$ against $I p$ and PL/LL showed that there seems to be a definite statistical relationship between these properties. The amount of scatter was, however, quite large. The curve obtained for $\left({ }^{\prime}{ }_{r} / u\right)$ plotted against $I p$ was similar to that shown by Voight, the curve obtained for $\left(\tau_{r}^{\prime} / \sigma\right)$ plotted against PL/LL is shown in Fig. 1. (As the residual cohesion always approaches zero, $\left(\tau_{\mathrm{r}}^{\prime} / \sigma\right)$ can be written as $\tan \phi_{\mathrm{r}}^{\prime}$.)

It can be seen from Fig. 1 that for each PL/LL point, three values of $\tan \phi^{\prime}{ }_{\mathrm{r}}$ are plotted. This is due to the fact that three shear box tests were carried out from one U4 sample, whereas index properties were obtained for the whole sample. It was observed, whilst plotting Fig. 1, that for most samples $\tan \phi_{\mathrm{r}}{ }_{\mathrm{r}}$ tends to decrease with increasing normal pressure, resulting in a 


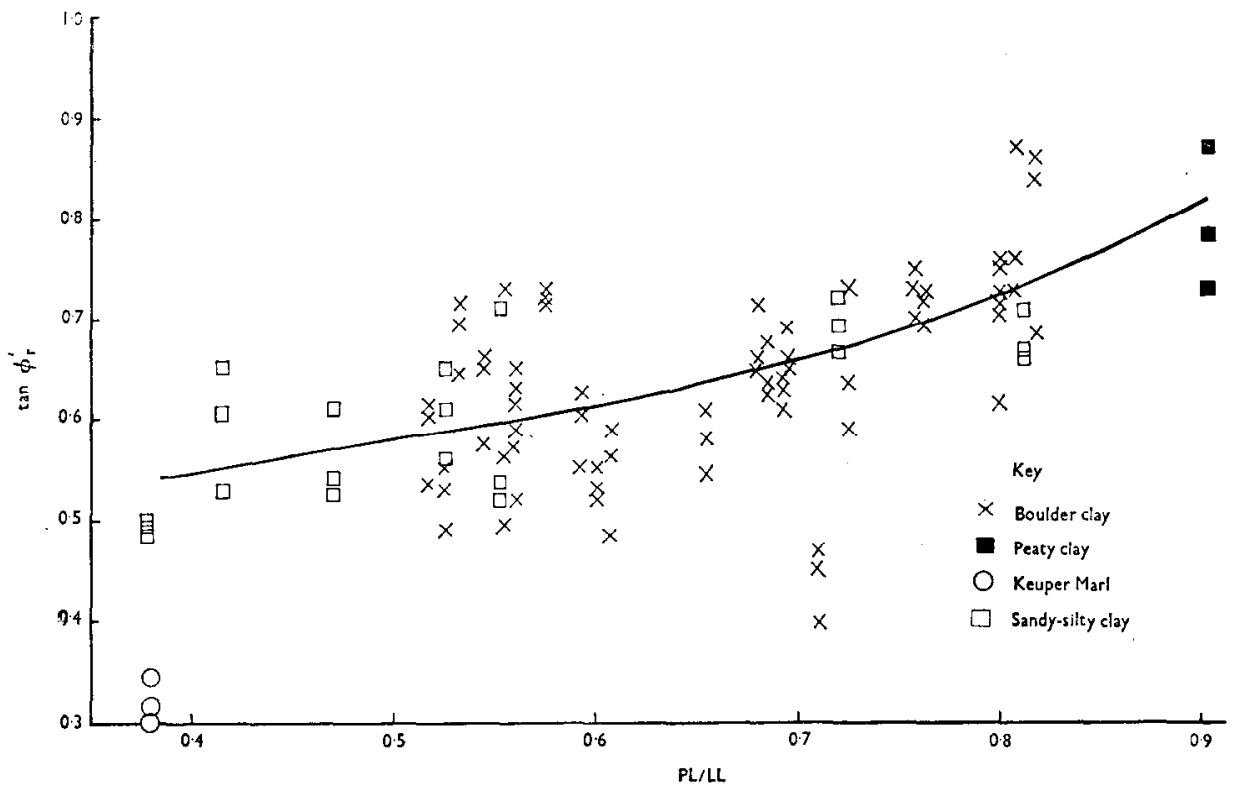

Fig. 1. Correlation between $\tan \phi_{r}^{\prime}$ and the ratio of plastic limit to liquid limit

residual cohesion intercept. Although the present plot was based on the assumption of $C_{\mathrm{r}}^{\prime}=0$ we believe that if the index properties for each residual shear box test were determined and the value of $C_{r}^{\prime}$ were taken into account the amount of scatter would have been greatly reduced.

Excluding the results of Keuper marl and one of the boulder clay samples, the figure shows a trend of increasing $\tan \phi_{\mathrm{r}}^{\prime}$ for increasing PL/LL. One possible reason for $\tan \phi_{\mathrm{r}}^{\prime}$ being very low for the Keuper marl sample may be that the silt-sized particles of Keuper Marl, which consist of conglomerated clay-sized particles, are broken up in the shear strength test (especially as in this case the test was carried out at fairly high normal pressures, $500-700 \mathrm{kN} / \mathrm{m}^{2}$ ), whilst in the liquid and plastic limit tests they remain intact. This would result in the LL and PL tests indicating that the Keuper marl particles are silt-sized whilst the shear strength test would be affected to some extent by the properties of the clay-sized particles.

\title{
Structural behaviour of residual soils of the continually wet Highlands of Papua New Guinea
}

\author{
WALLACE, K. B. (1973). Géotechnique 23, No. 2, 203-218.
}

\section{P. K. De and B. Furdas, Sir William Halcrow and Partners, Aberaman, Aberdare, Glamorgan}

Wallace is to be commended for his contribution on the structural behaviour of residual soils and the interpretation of the test results in terms of a structural model of the soil. However, every simplified structural model of soils has its limitations and the Author's model is by no means an exception.

We should like to take the opportunity of modifying the structural model to take into account certain physical properties of the residual soils and explain the behaviour of the soil in terms of 